\title{
Online Learning Element Design - DeVelopMent AND APPLICATION EXPERIENCES
}

\author{
Marnie V. Jamieson and John M. Shaw \\ Department of Chemical and Materials Engineering, Faculty of Engineering, University of Alberta \\ mvjamies@ualberta.ca and jmshaw@ualberta.ca
}

\begin{abstract}
The Capstone Design Course instructional team was selected to participate in the digital learning initiative at the University of Alberta. The goals of this initiative are to increase student engagement and promote flexible, independent learning. The objectives of the instructional team were to enhance the interactions between instructors and student design teams in the face of increasing enrolment and to align the course strategically with attributes expected for graduating engineers set out by the University of Alberta and elaborated in the Canadian Engineering Accreditation Board (CEAB) Guidelines. Existing course lecture materials were redeveloped into an asynchronous online format for individual student engagement. Related inclass team-learning activities were prepared and implemented. This report focuses on the design of online learning elements connected to in class active learning and project applications and our experiences with them over the course of a two-year pilot project. This paper is a follow up to "The University of Alberta Chemical Engineering Capstone Design Course Goes Flipped!’”
\end{abstract}

Keywords: Online Teaching, Flexible Learning, Blended Learning, Capstone Design, Learning Elements, Active Learning, Constructive Alignment, CEAB Assessment

\section{INTRODUCTION}

\subsection{Motivation}

The goals of the University of Alberta digital learning initiative (to promote flexible, independent learning and increase student engagement) were combined with the capstone design course instructional objectives (to enhance quality interactions between design instructors and student design teams). The Capstone Design Course in Chemical Engineering is a project course where approximately 25 teams of 5-6 students each complete a unique industry sponsored design project. Students must research their project, identify and compare competing options using sustainable design criteria, develop a team structure, a project plan and schedule and then complete their design project. The five capstone design instructors teach as a team in one section. [12]

\subsection{Literature Review}

Engineering students acquire and develop knowledge of fundamental concepts, gain skills required to apply knowledge to tasks, solve problems, construct and validate models, and evaluate data produced, while working effectively in teams whether in research, design or operations contexts $[13,20]$. How best to prepare students and to assist them to develop higher level cognitive and affective domain skills is a complex issue involving consideration of curriculum, policy, accreditation, pedagogy, and institutional leadership [7, $11,24]$. The traditional lecture format, where instructors transfer their knowledge to largely passive students continues to be the most widely used instructional approach in engineering education $[13,24]$, even though a growing body of education research indicates it is less effective than active instructional approaches $[13,19,20$, 24]. A recent review of discipline based education research (DBER) related to science and engineering found that:

... research-based instructional strategies are more effective than traditional lecture in improving conceptual knowledge and attitudes about learning. Effective instruction involves a range of approaches, including making lectures more interactive, having students work in groups, and incorporating authentic problems and activities [7, 20].

A number of factors may serve as barriers to the implementation of active learning approaches [3, 13], one being "the persistent myth that all active learning methods require more faculty time than lecturing" [24]. While active learning approaches may require additional development time initially, the use of constructive alignment [3] to design course material aligned with $\mathrm{CEAB}$ outcome assessment criteria can ensure coverage of content as well as opportunities for active learning [10], and is the primary benefit of the blended classroom.

Blended classrooms change the way instructors and students work together. A key aspect of the flipped approach is the integration of face-to-face and online (individual) learning with the aim of enhancing the classroom experience with active learning [25]. As such, a key feature of flipped learning is a shift from teachercentered lectures to student-centered instruction [25]. 
Flipped classroom approaches have the potential to enhance the quality of engineering education by providing opportunities for instructors to implement active learning strategies during class time. Currently, there is a limited body of research that has investigated flipped approaches within the context of engineering courses. However, there is evidence for the benefits of active learning approaches in engineering education [19, 21]. Where flipped or blended classes have been implemented in undergraduate engineering programs, there is evidence that student satisfaction is greater and that levels of class attendance, motivation, and collaboration among students is higher than in traditional lecture format courses [15]. Student engagement is widely acknowledged as important to their post-secondary success [1] and development of conceptual understanding [14]. The connection between student engagement and active learning is also well supported in the literature $[13,20]$. The impact of the implementation of a flipped classroom approach and active learning strategies on student engagement is a principal thread in the current study. Csikszentmihalyi's concept of flow $[4,16]$, wherein an individual is engaged when: they are intensely focused on their current activity, feel intrinsically rewarded and in-control, feel that the task is neither too difficult nor too easy, and may lose track of time (experience temporal distortion), underlies our work and is supported by Vygotsky's zone of proximal development[24] and Perry's pleasure zone[18].

\subsection{Problem Definition}

Previously, in the Chemical Engineering Capstone design course, lecture-format classes were provided in two-hour blocks twice weekly to support student learning and successful project completion. Thirty-minute team meetings with individual instructors, and open format question and work periods followed. The planned increase in enrolment from 125 students in 2015 to 200 students by 2018 requires more teams and this restricts the time for individual questions and meetings with instructors unless the in class instruction time is reduced.

\subsection{Solution Selected}

A blended course structure was developed using flipped classroom ideas and principles alongside technology advances in course delivery. Pre-class materials now typically comprise a brief video, a short reading, and a formative assignment to prepare students for in class interactive activities that apply online materials. Students submit brief assignment reports based on in class activities at the end of class. Post-class students apply their learning to their open-ended design projects. The short pre-class videos and supporting materials termed "Learning Elements" are the focus of this paper. Each topic area of the course includes the online learning elements, the in class active learning and activity and finally the design project application and is defined as a course module.

\subsection{Blended Classroom Learning Elements}

The blended capstone design course teaching plan development was launched by systematically mapping CEAB Graduate Attributes (GA) to course objectives. This process led to iterative revision of the existing course teaching plan, refinement of the learning objectives for students and the scaffolding needed for them to meet these learning objectives. The iterations were layered. The ability of students to demonstrate CEAB Graduate Attributes (an outcome) is related to the focus of the learning materials, activities and assessment criteria. The integration of these elements into the course required a rapid iterative design approach with overall department and faculty support for continuous and ongoing improvement of the course. It is the instructors' responsibility to design a course to allow students to demonstrate attainment of CEAB Graduate Attributes. It is the students' responsibility to engage with instructors, materials and assignments to provide evidence of attribute development. The faculty and the department are responsible for providing a collaborative environment where instructors are encouraged to and rewarded for designing courses focused on progressive and comprehensive student development of program objectives. Successful implementation necessitates contributions and collaboration from all stakeholders.

\section{LEARNING ELEMENT DEVELOPMENT}

Changing the lecture structure from a traditional one to online video and/or text based instruction with connected active learning in-class components is intended to enhance the intellectual development of students in their final term. The intent of the blended classroom is for students to work asynchronously to comprehend content presented in the video learning elements. Students apply, analyze, synthesize, and evaluate materials in teams and groups as part of in-class activities that culminate in a completed assignment. Opportunities for team discussion and integration of individual perspectives arise naturally, as do design project specific applications and knowledge extensions beyond the scope of individual assignments.

\subsection{Learning Element Design Begins with the Assessment Aligned Course Objectives and Student Intellectual Development Diversity}

In the blended version of the design course, on line learning elements expose students to team thinking 
processes and development from the outset. In their first assignment, students consider individual skills and the skills of their self-selected team members to determine where development is critical to project success. This information is used by students to resource their design project schedule, an experiential learning activity designed to enhance cognitive development and student development as life long learners. The alignment between course objectives and learning activities is made clear in this first assignment. The link between assessment and the principal course objectives and learning modules is also clear. Specifications for the final report relate directly to the course objectives, as do those for the situation report. The links to summative assessment are also established.

Diversity of intellectual development and engineering skills are two key challenges faced in the blended capstone course design, in general, and in the preparation of materials to support student learning, in particular. Frequent meetings between instructors and individual teams are central to student intellectual development. The role of the instructor as a guide is critical to intellectual development. Feedback from multiple instructors and industry contacts increases the diversity of perspectives and contexts students are presented with for consideration. Additional opportunities for student intellectual development, both in class and online, are incorporated into the blended course teaching plan. The learning elements support student cognitive and intellectual development.

\subsection{Learning Element Design Considers Student Intellectual Development}

The theories presented by Csikszentmihalyi[16], Vygotsky[24], and Perry[18] all suggest that a balance between the student's intellectual development (ability) and the cognitive objective (task) are required for learning to be engaging and satisfying, as illustrated in Figure 1. Learning activities must develop students both cognitively and intellectually. Vygotsky terms this "scaffolding" to enable learners to reach the zone of proximal development. Csikszentmihalyi describes this zone as the flow zone, where one loses track of time and experiences pleasure as a result of skill matching challenge. Research, writing and project-based assignments must have sufficient flexibility to address this balance because individual students approach activities from unique points on the spectrum of intellectual development and cognitive ability. Assignment requirements and scaffolding provide the impetus and the support for skill and knowledge development demanded by performance-based assessments such as the CEAB Graduate Assessment Attributes. In this course, on line learning elements were developed as short topical series of three or four approximately five minute long videos. The first learning element in a series provided background information at a level intended to be "easy" for all students. The next learning elements in a series progresses to more challenging materials.

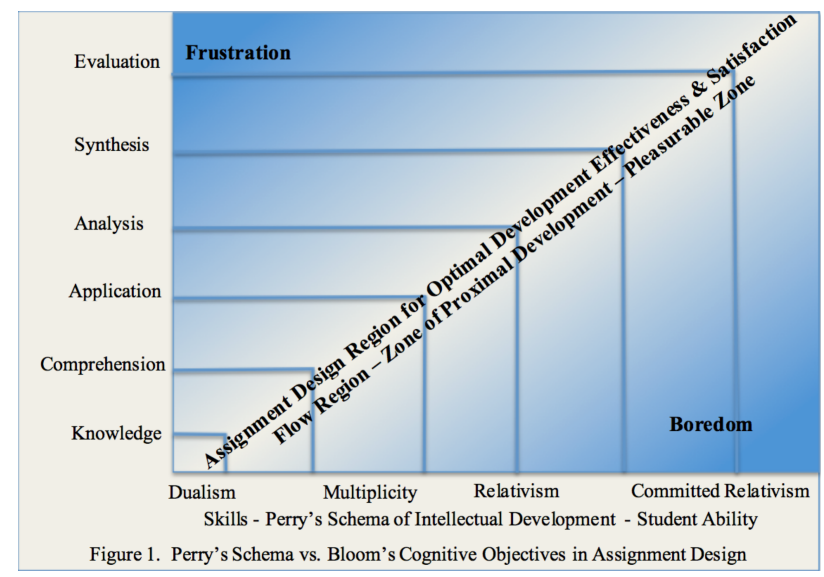

\subsection{Learning Element Design Considers Bloom's Taxonomy and the Design Process}

Design, in any discipline, is a process of alternating creative and critical thinking in an iterative pattern regardless of what is being designed [6]. It is an iterative process moving between the problem space and the solution space to create a product or a system to make a product for a user group. This creative and critical space is crucial for intellectual development, during design courses, and to be a successful designer professionally. Students may struggle with the design process partially because of their developmental stage along Perry's continuum and partially due to the lack of creative experience within a fundamentals focussed engineering curriculum [5]. From a cognitive task perspective this process can be described using the synthesis and evaluation terms of Bloom's Taxonomy. Development of these levels of learning depends on the previous levels of learning in the taxonomy. (Bloom, 1956) Synthesis is the classification for verbs such as: designing, composing, creating, integrating, predicting, combining and imagining. Evaluation is the classification for verbs such as: rating, judging, comparison and assessing theories. The combination of synthesis and evaluation actions applied iteratively is in effect the design process.

The sequencing of the learning module topics in the design course and within the learning elements themselves was deliberate. It imposes structure and guides students through this iterative process. In addition the guide / mentorship role of the instructors precludes retreat to earlier intellectual development levels described by Perry's Schema. 


\subsection{Learning Elements and CEAB Graduate Attribute Attainment}

Relating Learning elements to the CEAB GAA criteria early and developing linked concepts was found to be a useful structure for some learning elements. For technical content learning elements, the ideal structure was to start with examples most students would find easy and develop more complex ideas and concepts from there. Links to more complex ideas were developed using examples and animations in a progressive manner similar to that of a mentor explaining a concept. The first video was often basic. The second developed the intended application. The third video, which might stretch some students, included an application required for design project work completion. For some topics a fourth video was developed for enrichment. All topics were related to the course objectives and thus mapped to the CEAB Graduate Attributes.

\section{CREATING ON-LINE LEARNING ELEMENTS FOR THE DESIGN COURSE}

On-line learning elements typically comprising videos and supporting materials were created in three phases: the first ahead of the 2015 pilot, the second ahead of the 2016 pilot and the 2017 edition of the course. During the first phase over forty video elements were created for thirteen course modules ahead of and during the 2015 pilot. The second phase is now complete and includes revision to the first generation learning objects, based on feedback from students and teaching team members, and the creation of new learning elements ahead of the 2016 iteration of the course. During the second phase ten additional learning elements were created and text resource versions of all videos were added. The final phase will be completed later in 2016 and will incorporate learning from the second iteration of the pilot obtained through survey and interview data and input from education and engineering student evaluators. It is expected that this will be the final phase for editing and creation of learning elements. After this continual improvement and maintenance will be the focus rather than development.

\subsection{Learning Element Design and Testing}

Learning element creation was informed by experiences from other blended learning courses, University of Alberta Centre for Teaching and Learning seminars, and instructor evaluation. The preparation process rapidly became a collaborative and iterative design and learning experience. Prototype learning elements were prepared and revised following feedback from instructors prior to their use by students; later education (post 2015 pilot) and engineering (post 2016 iteration) student evaluators were employed. This was useful for determining the format to be used and the best tools to for developing and modifying on-line learning objects sustainably. This approach is known as the Successive Approximation Method (SAM) (Allen, 2012). SAM is similar to the ADDIE method except teaching materials are evaluated and revised before being tested in the classroom. The ambition to flip all the lectures led to several time crunches in developing and producing online materials for the 2015 pilot. This left room for further improvement of course materials to be used during the second pilot. Preparation of high-quality learning objects is essential for learning. This is time consuming and nontechnical content issues such as audio quality, text animation, and animation in synch with script highlighting, and audio links with visual cues all take time to master, and create a barrier for many instructors contemplating "going blended."

\subsection{Structure of Video Learning Elements}

Observing YouTube video clips and watching recorded lectures helped the teaching team form opinions on effective methods. Use of recorded lectures as a content delivery method was ruled out. However, full transcripts of the 2014 lectures including question and answer periods were available. The transcripts, prepared live to assist a hearing impaired student, were used as a starting point for script preparation along with the existing power point slide decks. During the review of transcripts, some repetition of material was identified. This repetition was not evident during live delivery. As rapid prototypes of the videos on specific topics were developed it became clear that:

- Live transcripts inform but are not a suitable basis for script preparation.

- Time compression for a 50-60 minute lecture was substantial. Equivalent video learning elements totaled at most 15-20 minutes.

- PowerPoint was a useful tool for story boarding and animation development.

- Animation action was needed to maintain focus on video learning elements. Some animation was completed in PowerPoint and some post production editing was performed using Camtasia.

- Shorter videos were found to be better than longer ones. About 5 minutes was found to be optimal.

- Teaching team members are good critics. They inform revisions much like team writing and editing is more effective for producing a quality product. Editing and feedback from teaching team members allowed for rapid and iterative development without student testing. 
- The preparation time is high. $20+$ hours for each learning object initially.

- The selection of audio/video tools impacted production quality and the time required to edit/modify videos.

\subsection{Audio Quality}

Audio quality proved particularly challenging. Learning elements were recorded using various methods, computers and microphones. It is difficult to watch a video with bad audio. Background noise, such as computer fans, is difficult to remove and reduces overall quality. Having a proper recording area with dedicated equipment and appropriate software is essential for producing high quality videos for student use. Quality counts. Attempts at using various tools for recording audio met with various degrees of success. Poor audio quality makes learning elements less effective and engaging for students. Recording issues are frustrating for instructors. Significant effort is expended in developing an engaging recording. Approximately two to three times the actual recording length is needed to obtain usable tracks. Repeating the process for sound quality issues and technical difficulties wastes instructor and production time. A high quality microphone connected to the final production software is essential. Conversion of sound files between programs can erode audio quality. This is not a place to "save" money in developing course materials. More time and money is required to do rework! Recording in Camtasia directly with a Yeti or gaming microphone in a very quiet location produces good results. Other options evaluated (computers with cooling fans, garage band converted to iTunes, SOM audio conversion, etc.) produced sub standard audio. Rerecording and significant additional editing were required to produce passable audio tracks using these approaches.

Table 1: Compression of Heat Exchanger Network Design Class and Module Structure Change.

\begin{tabular}{|c|c|}
\hline Learning Elements & $\begin{array}{c}\text { Times } \\
\text { [min:sec] }\end{array}$ \\
\hline Traditional Lecture & 60 \\
\hline Equivalent Video Learning & \\
• Hx Network Design & $9: 28$ \\
• Pinch Design & $5: 29$ \\
\hline Additional Video Learning & \\
$\bullet \quad$ Introductory (pre) & $2: 51$ \\
• Enrichment (post) & $4: 07$ \\
\hline
\end{tabular}

\section{RESULTS AND DISCUSSION}

\subsection{Delivery Time Compression}

Delivery times for the 2014 traditional lecture version of the course are compared on a class by class basis to the 2015 blended pilot in Figure 2. A detailed breakdown for the "Heat Integration" class "Class 10" in Figure 2, is provided in Table 1. New material was added to the online material for many classes, to enhance student learning, and an in class application was added. The time compression achieved varied from 1:2 to 1:6 depending on lecture materials being converted, the learning objectives for the class, and time spent crafting the learning elements.

Key learning from conversion and student feedback is summarized:

- 20 minutes is too long for video presentations students complained.

- $\quad$ Three five-minute videos are easier to watch than one fifteen-minute video.

- $\quad$ Pre class material is better received than post class material.

- $\quad$ Tuesday Post class material and Thursday pre class material are done at the same time.

- Post class material is sometimes viewed as optional.

- Connections among related learning elements must be explicit.

- $\quad$ Progression of a topic using multiple videos is a useful structure.

- Division of topics is equally useful for related concepts covered at the same depth.

- Learning elements are information dense - high compression rate.

- $\quad$ Time must be allowed for student processing.

- Written/illustrated notes supporting videos are effective and useful and should be included in learning element development.

- In class active learning is critical for students to make connections and process material.

- $\quad$ Online quizzes on pre class material are needed.

The capstone design class ends at 6:00pm after project meetings and intense work for most students and instructors. Most are tired and need a break. Having less work required before the Thursday class is better but not always possible in the topic progression. A student comments on the longer videos:

"Also, the videos are relatively long. I can't express how much easier it would be to come home after a [class] and read through/consult a document as opposed to sitting through a 20 minute video and then trying to 


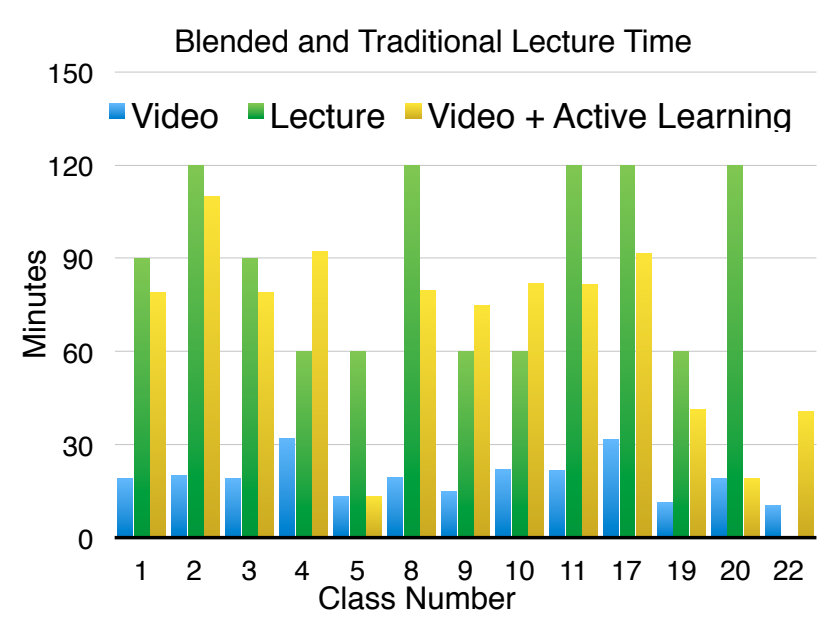

Figure 2. Structured Time Comparison

remember everything you've covered." (Design Student 2015)

After feedback on video length, the maximum length was reduced to a maximum of 10 minutes and the typical length was five minutes. Just because more material can go into a video format does not mean that it should. Time alone is not a good measure of content when comparing delivery methods. Our experience in searching for possible direct use video material was if video lengths were much greater than ten minutes we would not test it. We did not want to invest that much time in something that we weren't sure was going to suit our purpose. Most of the videos tested were listened to on the fastest speed to screen material for items of value. Like students, our time is limited and prioritized to get maximum benefit for time invested.

With compression in the delivery of materials, there is a temptation to add more material to "lectures". This is a mistake. Even though the material is compressed, it takes time for students to work with and to digest it. Reduction in learning element length compared to traditional lecture delivery does not mean material is eliminated. Rather, presentation of the material becomes illustrative and deliberate. Instructors no longer take cues from their students as to whether the material is too fast or too slow for understanding. The material is presented at the pace of the script and animation. Students may pause, replay, think about the material, and review accompanying written notes. These independent activities must be considered when calculating the pre class time equivalent of the lecture delivery method. Although material is compressed students still process information and make connections at a rate that is independent of the delivery method. The traditional lecture pace is approximately equal to the student processing pace. Students need time in class to work with an instructor and peers to develop a deeper understanding of content. The active learning component is essential to deeper learning.

\subsection{Assessment of Student Learning Element Use}

Assessment of student use of the on line material and demonstration of student use to ensure equivalent accreditation unit assessment for the capstone design course was a blended pilot project objective. Effectiveness measurements include: online quizzes, in class assignments, LMS access monitoring and equivalent student performance results. Student performance results for summative assessment are found to be equivalent on an average and individual result basis.

For the first two iterations of the blended course online quizzes were not included. Initially considered solely as a tool to assess access to online learning elements, time constraints dictated a focus on the development of learning elements and in class activities during the pilot project. Instructor observations during the pilot and questions posed by students during in-class activities underscore the utility of formative online quizzes to demonstrate student engagement with online material. These are now under development and will be included in the third iteration of the flipped course (winter 2017).

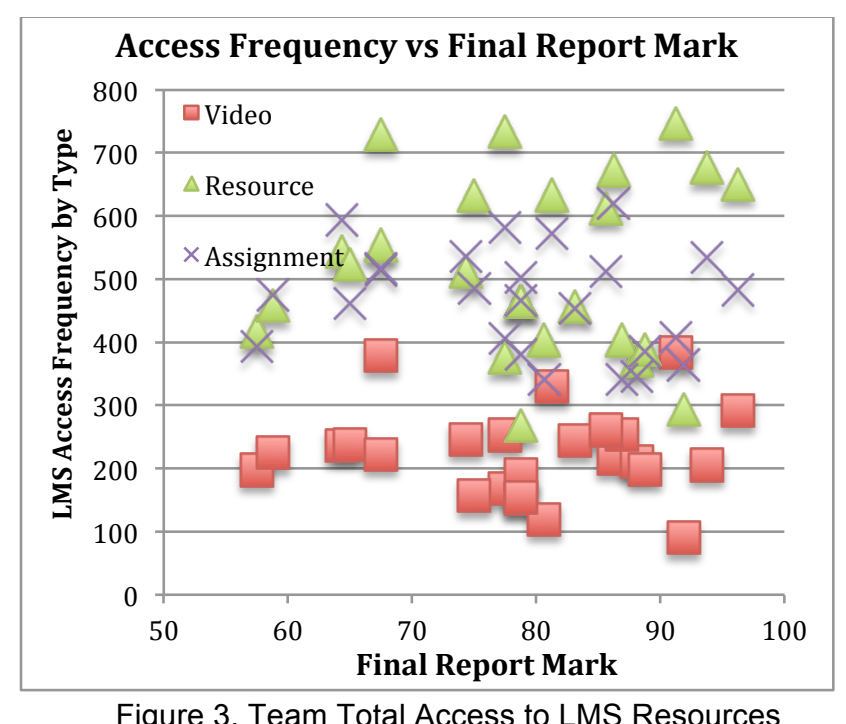

Figure 3. Team Total Access to LMS Resources Correlated with Final Report Marks

In class assignments were typically employed to ensure student interaction with the material and online access $\operatorname{logs}$ were used to evaluate access frequency. In class assignments typically required the students to engage with each other and submit a team assignment at the end of a class. Students also reported their findings to the class as a whole in some cases. Figure 3 shows no correlation with total team access and final report mark, but does indicate students accessed LMS materials during the course. 


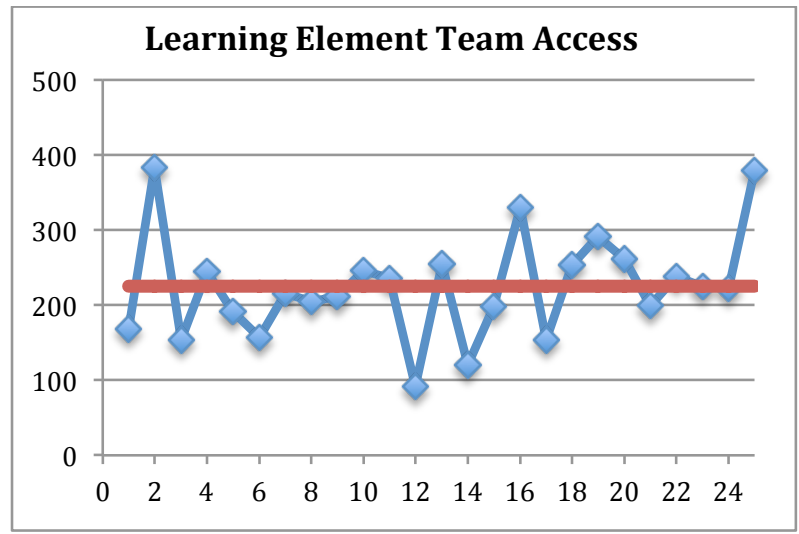

Fig. 4. Video Learning Element Access by Team

Observations and learning management system (LMS) $\log$ data indicate some teams watched the videos together, some individually and some skipped some of them. All teams watched most of the video learning elements, attended most class activities and handed in all assignments. Effectiveness is not evaluated on whether or not were able to check off all activities as complete but rather that students accessed materials necessary for their individual development and project completion. Students access online resources and are motivated to use them for their learning and/or project completion. Quality of resources and relevance to required project activities impact ongoing use of resources. Essentially students use what helps them complete project work and items that are required for course credit. They attempt to maximize project value for time spent. Figure 4 illustrates team use of video learning elements throughout the course. Similar variable patterns are observed for all LMS resources.

\section{CONCLUSIONS}

Ongoing evaluation and revision of on line material ahead of the third iteration of the course are aimed at clarity, brevity, organization, and enhancing connections with the diversity of student learning modalities and starting points on the spectrum of cognitive and intellectual development. This variation of active learning is time intensive for course developers and instructors.

\subsection{Engagement and Equivalent Learning}

All instructors reported increased student engagement and interaction during class and during weekly meetings with teams. Students participated in in-class activities and accessed required materials provided through the LMS. Instructors also observed that the depth and quality of questions students asked increased as their level of engagement increased.

The course web site on the learning management system was developed quickly. Negative student feedback centered on the usability of the web site, their difficulties in navigating through to access specific content, and video quality in some cases. Positive feedback was focused on team development, classroom interactions, presentation opportunities, and more project time.

\subsection{Learning Management System Access vs. Grades}

For the 2014 lecture version of the design course, just ahead of the pilot project, there is no correlation between course grade and access to resource materials provided on the LMS. The same finding holds for the 2015 flipped version of the course. Performance would appear to be linked to student centered factors rather than course delivery mode. Data analysis for the 2016 cohort is in progress.

\section{Acknowledgements}

We acknowledge with thanks the encouragement and support given throughout the pilot by Dr. Norma Nocente, Mr. Rishi Jaipaul and the Centre for Teaching and Learning production staff, the 2015, and 2016 cohorts of the Chemical Engineering Design course (CHE 435/465), and our teaching colleagues Mr. Frank Vagi and Mr. Len Church. The design course redevelopment was funded by the Provost's Office at the University of Alberta as part of campus wide digital learning initiative.

\section{References}

[1] Alexander Astin, What Matters in College?: Four Critical Years Revisted. San Francisco, CA: Jossey-Bass, 1993, 512 pp. \{ISBN: 978-0787-90838-9\}

[2] Ann E. Austin, "Promoting evidence-based change in undergraduate science education," in the Forth Committee Meeting on Status, Contributions, and Future Directions of Discipline-Based Education Research, (Washington, D.C.; 1 March 2011), 25 pp., 2011.

[3] J.B. Biggs, C.S. Tang, \& Society for Research into Higher Education, Teaching for quality learning at university: What the Student Does, (Maidenhead, McGraw-Hill Education. 2011), 389pp. \{ISBN: 978-0335-22126-4\}

[4] Mihaly Csikszentimihalyi, Flow: The Psychology of Optimal Experience. New York, NY: Harper \& Rowe, 1990, 303 pp. \{ISBN: 978-0060-16253-5\}

[5] Edward L. Cussler, "The future of the lecture," American Institute of Chemical Engineers Journal, Advance Online Publication, 11 pp., 2015.

[6] Kees Dorst, "The Core of 'Design Thinking' and Its Application,” Elsevier : Design Studies, 32 (6), pp. 521 532., 2011 
[7] Richard M. Felder, Rebecca Brent, and Michael J. Prince, "Engineering instructional development: Programs, best practices, and recommendations," Journal of Engineering Education, vol. 100, no. 1, pp. 89-122, 2011.

[8] Richard M. Felder and Michael J. Prince, "Inductive teaching and learning methods: Definitions, comparisons, and research bases," Journal Of Engineering Education, vol. 95, no. 2, pp. 123-128, 2006.

[9] Richard M. Felder and Michael J. Prince, "The case for inductive teaching," ASEE Prism, vol. 17, no. 2, pp. 55, 2007

[10] Donn R. Garrison and Norman D. Vaughan, Blended Learning in Higher Education: Framework in Principles, and Guidelines. San Francisco, CA: Jossey-Bass, 2008, 272 pp. \{ISBN: 978-0787-98770-1\}

[11] Donn R. Garrison and Norman D. Vaughan, "Institutional change and leadership associated with blended learning innovation: Two case studies," The Internet and Higher Education, vol. 18, pp. 24-28, 2013.

[12] Marnie V. Jamieson, "Application of Blended and Active Learning to Chemical Engineering Design Instruction", University of Alberta (2016)

[13] Nancy Kober, Reaching Students: What Research Says About Effective Instruction in Undergraduate Science and Engineering. Washington, D.C.: National Academies Press, 2014, 256 pp. \{ISBN: 978-0309-30043-8\}

[14] Priscilla Laws, David R. Sokoloff, and Ronald Thornton, "Promoting active learning using the results of physics education research," UniServe Science News, vol. 14, pp. 14-10, 1999.

[15] Elena Martínez-Caro and Francisco Campuzano-Bolarín, "Factors affecting students' satisfaction in engineering disciplines: Traditional vs. blended approaches," European Journal of Engineering Education, vol. 35, no. 5, pp. 473483, 2011.

[16] Jeanne Nakamura and Mihaly Csikszentimihalyi, "The concept of flow," Handbook of Positive Psychology, pp. 89-105, 2002.
[17] James A. Newell, Heidi L. Newell, and Kevin D. Dahm, "Rubric Development for Assessment of Undergraduate Research: Evaluating Multi Disciplinary Team Projects," Chemical Engineering Education, vol. 38, no. 1, pp. 68-73, 2004.

[18] Perry, William G. (1970). Forms of Intellectual and Ethical Development in the College Years: a scheme.” Holt, Reinhart and Winston, Inc. New York.

[19] Michael J. Prince, "Does active learning work? A review of the research," Journal of Engineering Education, vol. 93, pp. 223-231, 2004.

[20] Susan R. Singer, Natalie R. Nielsen, and Heidi A. Schweingruber, Discipline-based Education Research: Understanding and Improving Learning in Undergraduate Science and Engineering. Washington, D.C.: National Academies Press, 2012, 282 pp. \{ISBN: 978-0309-25411-3\}

[21] Leonard Springer, Mary Elizabeth Stanne, and Samuel S. Donovon, "Effects of small-group learning on undergraduates in science, mathematics, engineering and technology: A meta-analysis," Review of Educational Research, vol. 69, no. 1, pp. 21-52, 1999.

[22] Norman D. Vaughan, "A blended community of inquiry approach: Linking student engagement and course redesign," The Internet and Higher Education, vol. 13, no. 1, pp. 60-65, 2010.

[23] L.S. Vygotsky, L.S. (1978). Mind in Society: The Development of Higher Psychological Processes. Cambridge, Massachusetts: Harvard University Press.

[24] Phillip C. Wankat, "Progress in reforming chemical engineering education," Annual Review of Chemical and Biomolecular Engineering, vol. 4, pp. 23-43, 2013.

[25] John Watson, "Promising Practices in Online Learning: Blended learning: The convergence of online and face-toface education," North American Council for Online Learning, pp. 16, 2008. 